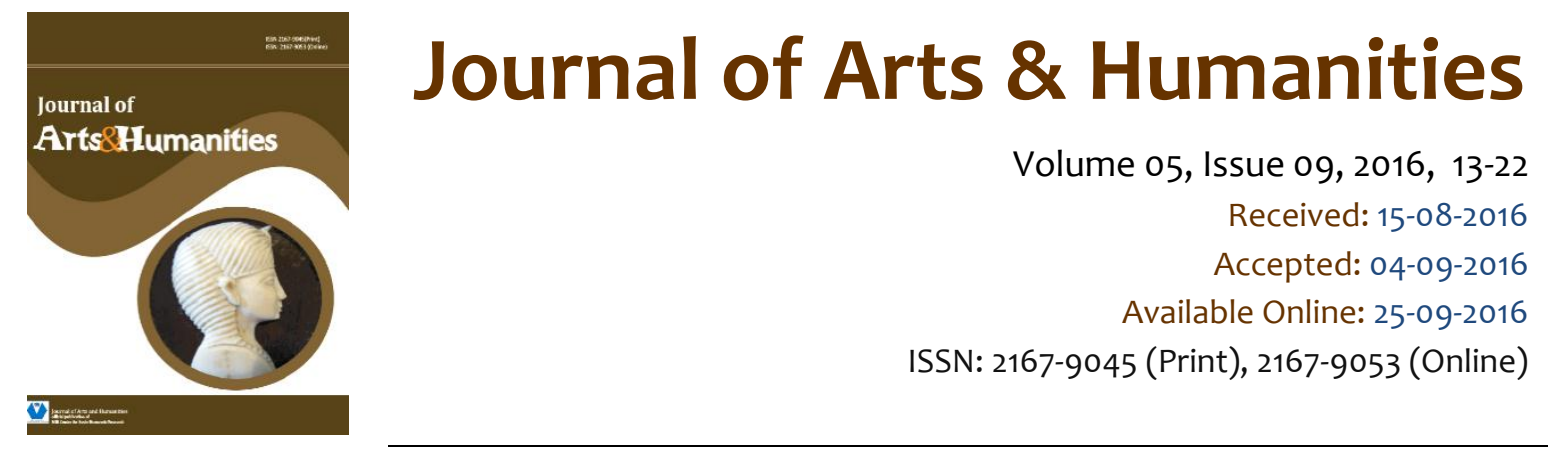

\title{
Implementing Multi-Media as a Pedagogical Tool in an EFL Classroom: Benefits and Barriers
}

\author{
Naiyer Azam Hashmi ${ }^{1}$
}

\begin{abstract}
The implementation of computer technologies especially the use of multimedia and internet in Saudi education system has attracted Arab students a lot. They have shown great interest in using computers technology for foreign language learning because computer technologies have transformed their contemporary society, changing the way they live, work and learn. As a response to such societal transformation, computer technologies have been brought into classrooms where they are considered to be effective in enhancing students learning and addressing certain education problems. The institutions of higher learning in Saudi Arabia have encouraged students and faculty members use multi-media and other related technologies in the classroom. To explore the benefits and barriers of implementing multimedia as a pedagogical tool in an EFL classroom, this study, through an interactive questionnaire, was conducted at the Preparatory Year, Najran University, Kingdom of Saudi Arabia. The focus group of the study was the students of level one and level two of the same semester i.e. the first semester 2015-16. The students were divided into two levels: Level one with 30 students ( 5 girls and twenty five boys) and Level two, with 30 students (six girls and twenty four boys). The interactive questionnaire had 8 items on the implementation of multimedia and the internet in an EFL classroom. Based on the findings of the interactive sessions, this study concludes that implementing multimedia and using internet and technology in EFL classrooms are highly motivating factors and help learners achieve their desired learning outcomes.
\end{abstract}

Keywords: EFL Classrooms, Foreign Language Teaching \& Learning, Internet, Implementation of Computer Technologies, Multimedia.

This is an open access article under Creative Commons Attribution 4.0 License.

\section{0}

\section{Introduction}

The present era assigns new challenges and responsibilities to the teacher. The trend of English language teaching has been drastically changed with the remarkable entry of the new technologies.

\footnotetext{
${ }^{1}$ Language Instructor, Dept. of English Language Skills, PYP, Najran University, K.S.A. E-mail: hhashmi38@yahoo.com
} 
Technology provides many options as making teaching interesting and more productive in terms of positive changes. Technology is one of the most significant drivers of both social and linguistic change. Researchers' state that technology lies at the heart of the globalization process; affecting mostly educational work and culture. The use of English language has increased rapidly after 1960 s and Saudi Arabia got no exception. At present, the role of English as it is the language of socio-political, sociocultural, educational, industrial, business, media, library, and key subjects in curriculum and language of imparting education, in Saudi Arabia, different teaching methods have been implemented to test the effectiveness of the teaching and learning process. One of the methods is the use of multimedia in the learning and teaching. Technology is utilized for the betterment of modern styles; it satisfies both visual and auditory senses of the students. With the rapid development of science and technology, the emerging and developing of multimedia technology and its application to teaching, featuring audio, visual, animation effects comes into full play in English class teaching and sets a favorable platform to reform and to explore on English teaching model in the new era. It's proved that multimedia technology plays a positive role in promoting activities and initiatives of student and teaching effectively in the classroom.

In language teaching and learning, we have a lot to choose from the world of technology: Radio, TV, CD Rom, Computers, the Internet, Electronic Dictionary, Email, Blogs and Audio Cassettes, Power Point, Videos, DVD's, and VCD's (Selasa, 2014). The last two decades have witnessed a revolution due to onset of technology, and has changed the dynamics of various industries, and has also influenced the industries and the way people interact and work in the society.

Computers and other information technologies such as video, telecommunications, and speechsynthesis, are playing increasingly more significant roles in Humanities classrooms. Pervasive and multifaceted, information technology is beginning to mirror all the traditional topics, methods, and goals of teaching (Bruce 1991). These wide-ranging applications raise the question: "What role should these technologies play in teaching and learning?"

Nowadays, computer and other related technologies are being used in TEFL/TESL classrooms for instruction in composition, literature, reading comprehension, spelling, vocabulary, grammar, usage, punctuation, capitalization, planning, reasoning, outlining, study skills, rhetoric, handwriting, drama, and virtually every other area of language arts (Bruce 1991). The curriculum designers have designed many programs specifically designed for pre-school, primary, upper elementary, middle school, high school, and college students, as well as students in adult education, English as a second language, foreign language, bilingual, and special needs classes.

Multi-Media and Internet have made a triumphal entry into the Saudi Arabian education system in the past few decades, and only an illiterate person would not accept that they have brought significant benefits to teachers and students alike. Most of the universities in the Kingdom of Saudi Arabia have equipped their lecture rooms and language labs with interactive whiteboards, data shows, e-podiums, Polycom video conferencing solutions and multi media centers. The solutions provided include a comprehensive learning management system, virtual classrooms, collaboration tools, content authoring and capturing tools, and digital repository systems. They have brought about a revolution in the teachers' perspective, as the teaching tools offered through the Internet were gradually becoming more reliable. Nowadays, the Internet is gaining immense popularity in foreign language teaching and more and more educators and learners are embracing it.

As a number of English learners are growing up, different teaching methods have been experimented to see the effectiveness of English language teaching. The use of technology in the form of films, radio, TV and tape recording has been there for a long time. Rana (2013) argued, "Technology has turned into one essential aspect of society that helps students to understand the bigger picture of the world and not just stay confined to what schools and teachers teach them within their classrooms". Rana further argues, "Technology isn't something that students need to be separated from; rather it's something 
that students need to embrace". Teachers can use multimedia technology to create more colorful and stimulating language classes. There are many techniques applicable in various forms to English language teaching situations now than in the past.

This study is an attempt to explore the benefits and barriers of implementing multimedia as a pedagogical tool in an EFL classroom. An interactive questionnaire was used at the Preparatory Year, Najran University. The focus group of the study was the students of level one and level two of the same semester. The students were divided into two levels: Level one with 30 students ( 5 girls and twenty five boys) and Level two, with 30 students (six girls and twenty four boys). The interactive questionnaire had 8 items on the implementation of multimedia and the internet in an EFL classroom. The concerned teachers were requested to share their classroom experience in the context of the contents of the interaction questionnaire. Based on the findings of the concerned teachers' response, the researcher observes that implementing multimedia and using internet and technology in EFL classrooms are highly motivating factors and help teachers and learners achieve their desired learning outcomes.

This study adapts an interactive questionnaire to elicit the teachers' feedback on the notion of implementation of multimedia and the internet in an EFL classroom. A section is devoted to define multimedia. Another section which illustrates the significant role of multimedia in teaching and learning process beautifies the article. This section discusses how multimedia enables learning through exploration, discovery, and experience and explains how, with multimedia, the process of teaching and learning can become more goal-oriented. It cites that multimedia enables learning to become fun and friendly. The study, then, ads a section on the benefits of applying multimedia in TEFL classroom followed by a section which spells out the obstacles and barriers to the use of multimedia in teaching and learning process. The findings and discussion section, which presents the concrete views elicited from the concerned teachers of every question on the interactive questionnaire, follows a conclusion where this study comes to an end.

\subsection{Methodology}

This study is based on an interactive questionnaire and was administered with 120 students studying at the Preparatory Year, Najran University, Kingdom of Saudi Arabia. The researcher chose two different levels: The students of level one and level two of same semester i.e. the first semester 2015-16.

The students were divided into two levels: Level one of first year preparatory year, with 30 students (5 girls and twenty five boys) and 2nd level, with thirty students (six girls and twenty four boys). The interactive questionnaire had 8 items on the implementation of multimedia and the internet in an EFL classroom.

\subsection{Multi-Media}

Multimedia means using more than one medium of expression or communication (of computer applications). Multimedia also means that computer information can be represented through audio, video, and animation in addition to traditional media (i.e., text, graphics drawings, and images).

A general definition is:

"Multimedia is the field concerned with the computer-controlled integration of text, graphics, drawings, still and moving images (Video), animation, audio, and any other media where every type of information can be represented, stored, transmitted and processed digitally". (Dave Marshall 2001)

Multimedia technology refers to interactive, computer-based applications that allow people to communicate ideas and information with digital and print elements. Professionals in the field use computer software to develop and manage online graphics and content. The work that media 
technology specialists produce is used in various media, such as training programs, Web pages, and news sites.

Implementing multimedia in an EFL environment has turned the classroom into a more dynamic and interactive place. Different types of investigations have been made to analyze the role and significance of multimedia in teaching English. These studies focused on investigating the consensus of the positive impact of multimedia on language pedagogy. One of the studies suggested the use of multimedia for the extraordinary benefits they carry into the classroom. It stated that multi-media nurture students' interests in a given field. It develops students' communicative competence. The study claimed that multimedia broadens students' insight to the global world and it enhances the pedagogy. Moreover, the use of multimedia provides authentic context of language as it exists in real life. It also shifts the learning process to be more "goal-oriented" and adjustable. For example, it has the power to lower students' affective filter as it is viewed to be entertaining. Therefore, learners are more comfortable to err.

\subsection{The Role of Multimedia}

Curriculum developers, intellectuals, educational leaders and policy makers claim that computers and related internet technologies represent important educational innovations (Howley \& Wood, 2011). Among them, multimedia plays the most significant role in teaching learning process especially teaching English as a foreign language. Multimedia enables learners to experience their subject in a vicarious manner. The key to providing this experience is having simultaneous, rather than sequential, graphics, video, and audio. The appeal of multimedia learning is best illustrated by the popularity of the video games currently available in the market (Johnstone and Milne, 1995).

Fuelling this growth are advances in technology and price wars that have dramatically lowered the cost of multimedia and computers. The growing number of Internet users has created a larger market for multimedia, and the new tools are enabling educators to become developers. Multimedia is used to enable individuals to create course material that once required teams of specialists, and individuals can now produce multimedia desktop video productions.

Multimedia enables learning through exploration, discovery, and experience. Technology does not necessarily drive education. That role belongs to the learning needs of students. With multimedia, the process of learning can become more goal oriented, more participatory, flexible in time and space, unaffected by distances, and tailored to individual learning styles and can increase collaboration between teachers and students. Multimedia enables learning to become fun and friendly, without fear of inadequacies or failure (Lu, Wan and Liu, 1999).

\subsection{The Benefits of Applying Multimedia in TEFL Classroom}

The findings of Amine, Benachaiba, and Guemide (2012) showed that most teachers and educators believed that employing multimedia enhances classroom quality. For example, multimedia gives students opportunities to display their previous knowledge through providing them with tools and applications to retrieve and elucidate information.

The study also found that most students believed that multimedia in classrooms will enhance their ability to use multimedia, which is a skill that has recently become a necessity. They consider multimedia a more beneficial tool that allows them to demonstrate knowledge and information in more depth and in shorter time. The pedagogy will become more interactive and inclusive of all students simultaneously.

The application of multimedia technology in English teaching may be exploited as:

1. To cultivate students' interest in study 
2. To promote students' communication capacity

3. To widen students' knowledge and to provide an insightful understanding of Western culture

4. To improve the effect of teaching

5. To improve interaction between teachers and students

6. To create context for language teaching and to provide flexibility in course context.

\subsection{The educational benefits of multimedia tools}

The educational benefits of multimedia can be observed from different perspectives. From an educator's perspective, multimedia tools do:

1. Provide students with opportunities to represent and express their prior knowledge.

2. Allow students to become designers in their learning process, using tools to access and interpret information, organize their personal knowledge, and represent what they know to others.

3. Engage students and provide valuable learning opportunities via applications.

4. Empower students to create and design rather than "absorbing representations created by others."

5. Encourage deep reflective thinking.

6. Create personally meaningful learning opportunities.

From a student perspective too, multimedia provide several educational advantages, which are as follows:

1. Students who experience the technical steps needed to produce effective multimedia documents will become better consumers of multimedia documents produced by others.

2. Students will learn the material included in a presentation in much greater depth than in traditional writing projects.

3. Students will work with the same information from four perspectives (Smith, 1993):

a) As researchers, they must locate and select the information needed to understand the chosen topic;

b) As authors, they must consider their intended audience and decide what amount of information is needed to give their readers an understanding of the topic;

c) As designers, they must select the appropriate media to share the concepts selected;

d) As writers, they must find a way to fit the information into the container, including linking to information for others to retrieve.

Moreover, the computers with multimedia technology offer opportunities for successful collaborative learning and teamwork in small groups. It also promotes interactive language teaching at the highest level. It is capable now of providing virtual learning settings such as classrooms and laboratories. It allows real interaction between the teacher and students at different places just as in a real classroom.

\subsection{Barriers to the Use of Multimedia in Teaching English}

While multimedia has a lot of advantages, there are some obstacles that prevent teachers to use it in their classrooms.

There are many barriers EFL teachers facing while using multimedia and computer technology in their instruction. I would like to review some of the important barriers toward using multimedia and computer technology in EFL instruction. They are: availability of hardware and software, teachers' lack of knowledge about multimedia, lack of experience, inadequate computer technology support, time factor, teacher attitudes, and lack of professional development in computer technology integration. A review of these barriers will indicate how they influence the teaching and learning processes and what could be done to urge EFL teachers to use computer technology in their instructions.

\subsection{Lack of time}


Teachers' inexperience of time management in computer labs causes not to use multimedia and computer technology appropriately in their teaching. The second problem is that it is very difficult to do technical activities in a very short time. These tasks need more time and more tools. The third problem is pertinent to the limitations of computer labs. According to Middleton, Flores, and Knaupp (1997), computers should be placed in classrooms so that students can access to them to use multimedia technologies in meaningful and practical ways.

\subsection{Lack of knowledge}

According to Mumtaz (2000), almost all teachers like to use internet and multimedia in their classrooms while teaching EFL/ESL but a lot of them either do not use it frequently or do not know how to appropriately utilize it. Teachers who do not use them frequently should develop and practice the necessary skills of computers. Suitable patterns are needed for infrequent users to perform technology. Lack of multimedia and computer knowledge is a barrier for teachers to use them in their classrooms. Many teachers need two or three years of experience to become smart users of computers in education. If teachers want to be skilled in applying technology in their classes they should have at least five years of experience in using it. Knowledge of teachers is an important factor for their success in the educational career.

\subsection{Lack of experience}

Rozell and Gardner (1999) opined that there is a connection between teachers' computer experience and their attitudes. The instructors who have more experience of using multimedia and other related technologies, they will show positive attitudes towards them. This is also stated that teachers with more years of teaching experience are less inclined to use technology in their language classroom instruction. Based on the findings of the above studies, it is concluded that teachers who have enough experiences in teaching their courses with the use of technology will use it into their instruction more than those who lack experience.

\subsection{Inadequate technological support}

One of the significant factors that impact the utilization of multimedia tools is the inadequate technological support. A study was done in the U.S. It indicated that the use of multimedia cannot be made effective without integrating it with computer technology. They are technical support, the lack of practical training, and lack of planning for computer technology integration. Teachers who are using multimedia and computer technologies in their classrooms need sufficient support from computer experts and should learn different software programs. Workshops and electronic message boards are the means that can motivate and support teachers who are using computer technologies (Boutler, 2007; Dupin-Bryant, 2004).

\subsection{Teachers' attitudes}

Using multimedia in EFL classrooms and integrating computer in the classes are so complicated that requires a change in the attitudes of teachers. This change is obtained in the long run. A study was conducted by Drent and Meelissen (2008). It was about the factors which restrict the usage of ICT by teachers. The results indicated that some factors like student-centered teaching, positive attitude towards using multimedia and ICT, and technological experience effect on the application of ICT by teachers.

\subsection{Lack of professional development}

One of the barriers that stop teachers learn how to use multimedia is insufficient teacher training (Bauer \& Kenton, 2005; Yang, 2008). In a study that was done by Yang (2008), it was exhibited that 
because of the lack of information technology experts, $46.3 \%$ of the 378 teachers stated that they did not have any professional development in computer technology integration. The type of training that teachers receive is also very important. In order to have a change in teachers' teaching methods, professional development must be content-focused and collaborative and this will certainly lead to students' learning (Li \&Protacio, 2010; Shi \&Bichelmeyer, 2007; Andree, Richardson, \& Orphanos, 2009). In sum, understanding the pedagogical, psychological and cognitive barriers to the successful use of multimedia and information technology may be a vital precondition for improving the utilization of computers and other technological aids in the educational process (Benzie, 1995). It is hoped that this research may be useful for the educators, policymakers and other decision makers who are directly involved in introducing Multimedia, CALL and ICT in EFL classroom in Saudi Arabia in particular and in the Middle East at large.

\subsection{Findings and discussion}

The following section presents the findings and discussions on the contents of the interactive questionnaire as mentioned in the methodology:

7.1 Do you use multimedia and internet in your classrooms? Is it motivating for learning EFL?

Based on the interactions, both 1st and the 2nd level students believe that multimedia is useful for teaching English. Generally, students believe that the technology used in EFL classrooms motivates them. To be more specific, approx. $87.5 \%$ think that technology always increases their motivation about EFL. It was also revealed that the students were not taught using multimedia in their secondary schools.

\subsection{Should teachers use multimedia technology for every lesson?}

Based on the interactions outcome, approx. $94 \%$ of the students believe that EFL would be improved if technology is used for every lesson. According to the students, this use will arouse their interests in EFL and encourage them attend every class resulting not to miss any lecture because of the different technological devices used for different presentations.

\subsection{Do authentic materials downloaded from Internet and used by teachers make learning} process active?

Based on the interactions with students, $66 \%$ believe that what teachers download from the internet is ineffective. This result is not very encouraging and shows that a downloaded projection block of documents is less appreciated by students because this material negatively affects their learning process. According to students, teachers still have a great responsibility, and authentic materials cannot completely replace teachers in class. Teachers must be skilled enough to use Information and Communication Technologies (ICTs) and should know how to plan lectures with the new materials of technology.

\subsection{Do computer-based teaching activities make lessons more enjoyable?}

Based on the interactions with students, it is noted that computer-based classrooms make lessons more enjoyable and agree that these classrooms never make lectures boring and unnecessary. In contrast, multimedia and technology provide students with the ability to understand the lectures better.

7.5 Do you think that technological devices should always be used in EFL classrooms to increase your motivation? 
Based on the interactions and to understand the perspective of improving the learning process in EFL classroom, almost $90 \%$ agree that technological materials are always needed in classrooms. These students want to see different technological devices used for motivation. This finding justifies our interpretations of above results that summarize the regression to the way that the media is used.

\subsection{Do lectures seem more interesting and enjoyable when the teacher uses Power Point Presentations?}

Based on the interactions with students, all agree that lessons and lectures can be more enjoyable with Power Point Presentations. For example, the researcher has been teaching a class and using different Power Point Presentations in class for years. The researcher noted that students always enjoy the lectures presented using PPP and have no difficulties in understanding these presentations.

\subsection{Do you think that tutorial videos, films, and CDs can be helpful for developing EFL skills?}

Based on the interactions notes, all students agree that tutorial videos, films, and CDs are always helpful for developing EFL skills. Tutorial videos always make lectures easy to understand because these videos provide several practical ways of how to act or solve problems in EFL.

\subsection{Do you think that projects should be presented using multimedia technology?}

Based on the interactions, $75 \%$ of students believe that technological devices should be used to present research based- projects. This result shows that through the computer, a course can be prepared and presented in different ways. The possibilities offered by digital computers make a course more interesting. Several students had already practiced presenting their research projects using visuals aids and Power Point Presentations, which was appreciated by their teachers and mates.

\subsection{Conclusion and recommendations}

This research suggests that implementing multimedia and using internet and technology in an EFL classroom are very important and highly motivating factor for students. It offers many benefits to enhance teaching and learning. Most importantly, technology integration has the potential to increase students' motivation. All students attend the class regularly because the course seems interesting, in contrast to the traditional classroom environment, which seems boring and for which students lack the skills necessary to succeed.

With multimedia, the students get familiarity with academic vocabulary and language structure and connecting with the Internet provide students a great motivation. Students seem to begin class and often arrive early at the classroom. They also often stay after class to continue working on the class or home assignments. Overall, students develop greater confidence in their ability to use English because they interact with the Internet through different language skills.

Multimedia provides students gather information that encourages their imaginations and interests. Since all classrooms nowadays are equipped with technology, students feel confident in their ability to accomplish their tasks due to their familiarity with multimedia technology. The researcher noted that the students presented their tasks using Power Point Presentations and videos downloaded from internet. These students were excited about the opportunity to show their skills and viewed the tasks as challenging and engaging.

It is established, perhaps, that one of the ultimate goals of multimedia in language teaching is to promote students' motivation and learning interest and the use of multimedia is a practical way to get 
students involved in language learning. It is hoped that, in future, the use of multimedia in English teaching will be further strengthen. The process of EFL teaching and learning will be more studentcentered but less time-consuming.

In sum, the researcher believes that implementation of multimedia in an EFL classroom will not only improve students' linguistic skills but also will be helpful to ensure an effective result of teaching and learning process. It is expected, except a few issues, that the use of multimedia technology in the classroom can be used effectively with proper computer knowledge on part of teachers and learners.

\section{References}

Alfahad, F. (2009). Students' attitudes and perception towards the effectiveness of mobile learning in King Saud University, Saudi Arabia. The Turkish Online Journal of Educational Technology, 8(2), 111119.

Amin, B., Benachaiba, C., \& Guemide, B. (2013). Using multimedia to motivate students in EFL classrooms: A case study of English master's students as Jijel University, Algeria.

Bruce, B. (1991). Roles for computers in teaching the English language arts. In J. Jensen, J. Flood, D. Lapp, \& J. Squire (Eds.), Handbook of research on teaching the English language arts (pp. 536-541). New York:

Macmillan. Also as Technical Report No. 522 (1990, December). Urbana, IL: University of Illinois, Center for the Study of Reading.

Egbert, J. (2004). Mediating the digital divide in CALL classrooms: Promoting effective language. ReCALL, 16(2), 280-291.

Faruk, S. M. G. (2014) Saudis' attitude towards English: trend and rationale. PCTS Proceedings (Professional Communication \& Translation Studies), 7(1/2), 173-180.

Felix, U. (1998). "Virtual language learning, finding the gems amongst the pebbles", Melbourne: Language Australia Ltd.

Howley, A., Wood, L., \& Hough, B. (2011). Rural elementary school teachers' technology integration. Journal of Research in Rural Education, 26(9). Retrieved http://jrre.psu.edu/articles/26-9.pdf.

Johnstone, J. \& Milne, L. (1995) 'Scaffolding second language communicative discourse with teachercontrolled multimedia', Foreign Language Annals, 28,(3):315-29.

Macmillan Dictionary | Free English Dictionary and Thesaurus Online. (2015). Retrieved May13, 2015, from http://www.macmillandictionary.com/us

Merriam-Webster Online Dictionary. (2015). Retrieved May 13, 2015, from http://www.merriamwebster.com

Mudge, S. M. (1999). Delivering multimedia teaching modules via the Internet. Innovations in Education and Training International 36(1): 11-16.

Najjar, L. J. (1996). Multimedia information and learning. Journal of Multimedia and Hypermedia 5: 129150.

Rana, Prajesh SJB. (2013) Education and the Use of Technology. Republica The Week: 12.

Selasa (2014, October 24) "Use of Technology in English Language Teaching and Learning" : An Analysis.

[Web log post] Retrieved from http://salsabilapurnamasari.blogspot.com/2014/10/use-of-technology-inenglish-language.html

Warschauer, M. and D. Healey. (1998). Computers and language learning: An overview. Language Teaching 31: 57-71.

Warschauer, M. (1996). Computer-assisted language learning: an introduction. In S. Fotos (Ed.), Multimedia language teaching, pp. 3- 20. Tokyo: Logos International.

Warschauer, M., \& Kern, R. (2005). Network-based language teaching: Concepts and practices. Cambridge: Cambridge University Press. 
Appendix 1: The interactive questionnaire

1-Do you use multimedia and internet in your classrooms? Is it motivating for learning EFL?

2- Should teachers use multimedia technology for every lesson?

3- Do authentic materials downloaded from the Internet and used by teachers make the learning process active?

4-Do computer-based teaching activities make lessons more enjoyable?

5- Do you think that technological devices should always be used in EFL classrooms to increase your motivation?

6-Do lectures seem more interesting and enjoyable when the teacher uses Power Point presentations?

7- Do you think that tutorial videos, films, and CDs can be helpful for developing EFL skills?

8- Do you think that projects should be presented using multimedia technology? 